\title{
Effects of Sarilumab on Rheumatoid Arthritis as Reported by Patients Using the Rheumatoid Arthritis Impact of Disease Scale
}

\author{
Laure Gossec (i), Vibeke Strand (D), Clare Proudfoot, Chieh-I Chen, Sophie Guillonneau (D), \\ Toshio Kimura, Hubert van Hoogstraten, Erin Mangan, and Matthew Reaney
}

ABSTRACT. Objective. We evaluated the effect of sarilumab on patient-perceived impact of rheumatoid arthritis (RA) using the 7-domain RA Impact of Disease (RAID) scale.

Methods. Two phase III, randomized, controlled trials of sarilumab in patients with active, longstanding RA were analyzed: (1) sarilumab $150 \mathrm{mg}$ and $200 \mathrm{mg}$ every 2 weeks plus conventional synthetic disease-modifying antirheumatic drugs (+csDMARD) versus placebo + csDMARD [TARGET (NCT01709578)]; and (2) sarilumab $200 \mathrm{mg}$ versus adalimumab (ADA) $40 \mathrm{mg}$ monotherapy [MONARCH (NCT02332590)]. Least-squares mean (LSM) differences in RAID total score (range 0-10) and 7 key RA symptoms, including pain and fatigue (baseline to Weeks 12 and 24), were compared. "Responders" by RAID total score were defined by improvements from baseline $\geq$ minimal clinically important difference (MCID), and $\geq$ patient-acceptable symptom-state (PASS) at endpoint.

Results. Sarilumab $150 \mathrm{mg}$ and $200 \mathrm{mg}+$ csDMARD were nominally superior $(\mathrm{p}<0.05$ ) versus placebo + csDMARD and $200 \mathrm{mg}$ sarilumab versus ADA $40 \mathrm{mg}$ in LSM differences for RAID total score at weeks $12(-0.93$ and $-1.13 ;-0.49$, respectively) and $24(-0.75$ and $-1.01 ;-0.78)$, and all effects of RA (except functional impairment in MONARCH Week 12). Effects were greater in physical domains (e.g., pain) than mental domains (e.g., emotional well-being). More patients receiving sarilumab versus placebo or ADA reported improvements $\geq$ MCID and PASS in total RAID scores at both assessments.

Conclusion. Based on the RAID, sarilumab + csDMARD or as monotherapy reduced the effect of RA on patients' lives to a greater extent than placebo + csDMARD or ADA monotherapy. (ClinicalTrials.gov: NCT01709578 and NCT02332590) (First Release August 1 2019; J Rheumatol 2019;46:1259-67; doi:10.3899/jrheum.180904)

Key Indexing Terms:

RHEUMATOID ARTHRITIS RHEUMATOID ARTHRITIS IMPACT OF DISEASE SCALE DISEASE-MODIFYING ANTIRHEUMATIC DRUGS

From the Sorbonne Université, Institut Pierre Louis d'Epidémiologie et de Santé Publique (UMRS 1136), GRC-UPMC 08 (EEMOIS); Rheumatology Department, Hôpital Pitié Salpêtrière, AP-HP, Paris, France; Stanford University, Palo Alto, California, USA; Sanofi, Guildford, UK; Regeneron Pharmaceuticals Inc., Tarrytown, New York, USA; Sanofi, Paris, France; Sanofi, Bridgewater, New Jersey, USA.

Supported by Sanofi and Regeneron Pharmaceuticals Inc., which developed sarilumab. L. Gossec has acted as a consultant for Sanofi. $V$. Strand has acted as a consultant for Regeneron Pharmaceuticals Inc. and Sanofi. C. Proudfoot is a former employee of and current shareholder in Sanofi and current employee and shareholder of Novartis. C. Chen,

T. Kimura, and E. Mangan are employees of and shareholders in

Regeneron Pharmaceuticals Inc. E. Mangan is also a shareholder in

Pfizer. S. Guillonneau and H. van Hoogstraten are employees of and hold shares or options in Sanofi.

L. Gossec, MD, PhD, Sorbonne Université and Rheumatology Department, Hôpital Pitié Salpêtrière, Institut Pierre Louis d'Epidémiologie et de Santé Publique (UMRS 1136), GRC-UPMC 08 (EEMOIS); V. Strand, MD, Stanford University; C. Proudfoot, PhD, Novartis; C.I. Chen, MPH,

Regeneron Pharmaceuticals Inc.; S. Guillonneau, MSc, Sanofi;

T. Kimura, MSc, Regeneron Pharmaceuticals Inc.; H. van Hoogstraten, MD/PhD, Sanofi; E. Mangan, PhD, Regeneron Pharmaceuticals Inc.;

$M$. Reaney, $M S c$, formerly of Sanofi.

Address correspondence to M. Reaney, 3 Forbury Place, 23 Forbury Road, Reading, RG1 3JH,UK.E-mail: matthew.reaney@iqvia.com

Full Release Article. For details see Reprints and Permissions at jrheum.org Accepted for publication February 6, 2019.
Patients with rheumatoid arthritis (RA) experience a variety of signs and symptoms, and report significant physical and psychological effects with this condition ${ }^{1,2,3}$. Quantifying key clinical symptoms and effects of RA from the patient perspective, in addition to evaluating clinical markers, is therefore vital to comprehensively understand the disease and evaluate treatment, in accord with current international consensuses and guidelines ${ }^{4,5,6,7}$.

The patient perspective can be systematically collected through administration of patient-reported outcomes (PRO). In addition to physician-reported and laboratory data, use of well-defined and reliable PRO is essential for drawing comprehensive conclusions for RA treatment outcomes. The RA Impact of Disease (RAID) scale is an internationally validated, composite PRO measure specifically designed for use in $\mathrm{RA}^{8,9,10,11,12}$. RAID evaluates 7 domains, each containing a single item, including 2 key symptoms (severity of pain and fatigue), and 5 primary impacts (coping, emotional and physical well-being, functional impairment, and sleep). It also provides additional information for

Personal non-commercial use only. The Journal of Rheumatology Copyright @ 2019 . All rights reserved. 
assessment of RA, such as coping and emotional well-being, compared with the traditionally evaluated PRO of patient global assessment of disease activity, pain, and physical functioning $8,13,14,15$.

Sarilumab is a recently approved human monoclonal antibody directed against both soluble and membrane-bound interleukin 6 receptor- $\alpha$ (anti-IL-6R $\alpha$ ). The RAID scale was administered to patients in 2 phase III randomized controlled trials (RCT) of sarilumab: TARGET (NCT01709578) ${ }^{16}$ and MONARCH (NCT02332590) ${ }^{17}$. Change from baseline in the RAID score was a secondary endpoint in both the TARGET and MONARCH RCT.

TARGET compared the efficacy and safety of subcutaneous (SC) sarilumab $150 \mathrm{mg}$ and $200 \mathrm{mg}$ every 2 weeks (q2w) versus placebo plus conventional synthetic disease-modifying antirheumatic drugs (csDMARD) in patients with moderate to severely active RA who were intolerant of or had an inadequate response to $\geq 1$ tumor necrosis factor inhibitor $(\mathrm{TNF}-\mathrm{IR})^{16}$. The co-primary endpoints in TARGET were the proportion of patients achieving American College of Rheumatology $\geq 20 \%$ (ACR20) responses ${ }^{7}$ at Week 24 , and change from baseline in physical function assessed by the Health Assessment Questionnaire-Disability Index (HAQ-DI) ${ }^{18}$ at Week 12.

MONARCH compared the efficacy and safety of sarilumab SC 200 mg q2w monotherapy versus adalimumab (ADA) SC $40 \mathrm{mg}$ q2w monotherapy in patients with active RA who discontinued treatment with methotrexate $(\mathrm{MTX})^{17}$. The primary efficacy endpoint in MONARCH was change from baseline in the 28-joint Disease Activity Score using erythrocyte sedimentation rate at Week 24 . In both these RCT, sarilumab showed superiority over placebo or ADA in reducing signs and symptoms of RA and improving physical function, and its safety profile was consistent with IL-6R blockade ${ }^{16}$.

The RAID is recognized by researchers, patients, and organizations such as the European League Against Rheumatism $(\text { EULAR })^{19}$ and OMERACT ${ }^{20}$ as a promising instrument, because it was developed with patient input and addresses all the key issues for patients with RA. However, as a relatively new scale, the RAID has to date been applied in few clinical trials ${ }^{15,21}$ other than TARGET ${ }^{16}$ and MONARCH ${ }^{17}$, with publications for these trials describing only high-level data on the RAID.

Our report contributes to further validating the RAID score. Our objective was to assess the effects of sarilumab treatment in combination with csDMARD or as monotherapy on the patient-reported impact of RA using the RAID scale.

\section{MATERIALS AND METHODS}

Data were collected from 2 phase III RCT of sarilumab, TARGET and MONARCH, as described ${ }^{16,17}$. Both trials enrolled adult patients fulfilling the 2010 ACR/EULAR classification criteria for RA ${ }^{22}$. In TARGET, TNF-IR patients with moderate to severely active RA were included if disease duration was $\geq 6$ months. Patients with uncontrolled concomitant diseases, significant extraarticular manifestations of RA, functional class IV RA, other inflammatory diseases, or current/recurrent infections or those receiving prednisone were excluded.
In MONARCH, patients with moderate to severely active RA with ACR class I-III functional status ${ }^{23}$ were enrolled if they had disease duration $\geq 3$ months, and no prior use of biologic DMARD. Eligible patients were randomized to sarilumab SC $200 \mathrm{mg}$ plus placebo q2w or ADA SC $40 \mathrm{mg}$ plus placebo $\mathrm{q} 2 \mathrm{w}$ for 24 weeks. After 16 weeks, patients who did not achieve $\geq 20 \%$ improvement in tender and swollen joint counts in the sarilumab group were switched to once-weekly ADA or matching placebo ${ }^{17}$.

RAID scale. The RAID scale consists of 7 single-item domains, each rated by patients on an 11-point numerical rating scale from 0 (best) to 10 (worst) ${ }^{8}$. There are 2 symptom domains, pain and fatigue, and 5 impact domains, consisting of functional impairment, emotional well-being, physical well-being, quality of sleep, and ability to cope. The domains can be reported separately ${ }^{14}$ and as a total score, which is a continuous variable ranging from 0 (best) to 10 (worst); lower scores are indicative of less impact of disease. In the total RAID score, each domain is given a specific weight reflecting its importance to patients (e.g., more given to pain, fatigue, and functional impairment). Weights were obtained from international studies, as follows: pain 0.21 ; functional disability 0.16 ; fatigue 0.15 ; and sleep problems, emotional well-being, physical well-being, and coping all $0.12^{8,10}$. The RAID scale has been psychometrically validated at an international level $1^{8,10,12,24}$.

Statistical analyses. Least-squares mean (LSM) differences from baseline in total RAID and domain scores were analyzed with a mixed model for repeated measures, including treatment, region, visit, and treatment-by-visit interaction (and number of prior TNF inhibitors in TARGET) as fixed effects and baseline as a covariate.

Posthoc analyses were conducted to identify responders in the total RAID score. Three "responder" definitions were used. Two were based on an established minimal clinically important difference (MCID) from baseline. This was previously defined by different techniques using data from 108 patients receiving TNF inhibitor treatment for active RA, who were evaluated at screening and baseline, then after 4 and 12 weeks of treatment ${ }^{11}$. The reliability of the overall RAID score, and various possible improvement thresholds proposed in the rheumatology scientific literature [e.g., improvements of at least 1,2 , or 3 points in total RAID score (total range 0-10 points), and relative changes $\geq 20 \%, 30 \%$, and $50 \%$ from baseline ${ }^{24,25}$ were evaluated. The reliability of the RAID score between screening and baseline was found to be high [intraclass correlation coefficient of $0.85(95 \% \mathrm{CI}$ $0.79-0.90)$ ], with smallest detectable difference of 1.8 and smallest detectable change of 1.3. The 2 optimal MCID thresholds were identified as a 3-point reduction in total RAID score from baseline, or a relative improvement of $50 \%$ in total RAID score. A patient was defined as a responder if they reported improvements from baseline $\geq$ MCID. A third responder definition was based on a patient acceptable symptom state (PASS), defined as a score $\leq 3^{11}$. Patients who discontinued therapy or required rescue medication prior to achieving responder endpoints were classified as nonresponders ${ }^{26,27,28,29}$

In TARGET, RAID was positioned after the break in the hierarchy used to control for multiple testing, and therefore statistical significance cannot be determined; other analyses were conducted posthoc. In MONARCH, RAID was not included in the hierarchy. Thus, to aid interpretation, statistical comparisons between treatment groups (to test for nominal significance) were supplemented by between-group effect size analyses (standardized mean differences) using Cohen's d Rule for Change Interpretation, as follows: important: $\mathrm{d} \leq-0.8$; moderate: $-0.8<\mathrm{d} \leq-0.5$; and small: $-0.5<\mathrm{d} \leq-0.2^{30}$

RAID scores were separately evaluated in each trial at baseline and at Week 12 and Week 24. For missing data at the item level, an imputation using the mean of the 6 other items was used.

Analyses in this study were conducted on data from 2 previous RCT of sarilumab, TARGET (NCT01709578) and MONARCH (NCT02332590) ${ }^{16,17}$ The protocols for both these studies were approved by the appropriate ethics committees/institutional review boards, and each patient provided written informed consent before participation in the studies. The studies were conducted in compliance with the International Conference on Harmonization Guidelines for Good Clinical Practice and the Declaration of Helsinki ${ }^{16,17}$.

Personal non-commercial use only. The Journal of Rheumatology Copyright $\subset$ $\subset$ 2019. All rights reserved 


\section{RESULTS}

Overall, 546 patients from TARGET and 369 from MONARCH were included in the analysis (Table 1). Between-group baseline demographics were generally comparable within each study; however, in MONARCH, disease duration was longer in the sarilumab group versus the ADA group [mean 8.1 yrs (SD 8.1) vs mean 6.6 yrs (SD 7.8), respectively]. Between studies, mean disease duration in MONARCH was shorter than in TARGET (mean $7.3 \mathrm{yrs}$ vs mean 12.1 yrs). Baseline RAID scores were generally comparable across all groups within the individual RCT, ranging from a mean of 6.5 (SD 2.0) to 6.8 (SD 1.8) in TARGET ${ }^{31}$ and 6.4 (SD 2.0) to 6.7 (SD 1.7) in MONARCH ${ }^{17}$ (Table 1). All other demographics, including age, sex, and race, were relatively comparable among the patients in the 2 studies.

Changes in RAID score from baseline. LSM differences in RAID total scores were greater with sarilumab compared to placebo in the TARGET study at Week $12(-0.93$ and -1.13 , respectively, for sarilumab $150 \mathrm{mg}$ and $200 \mathrm{mg}$ vs placebo; nominal $\mathrm{p}<0.0001)$ and Week $24(-0.75$ and -1.01 , respectively, for sarilumab $150 \mathrm{mg}$ and $200 \mathrm{mg}$ vs placebo; nominal $\mathrm{p}<0.01)$. LSM differences in RAID total score were also greater with sarilumab versus ADA in MONARCH at Week 12 ( -0.49 for sarilumab $200 \mathrm{mg}$ vs ADA; nominal $\mathrm{p}<0.05$ ) and Week 24 ( -0.78 for sarilumab $200 \mathrm{mg}$ vs ADA; nominal $\mathrm{p}<0.001$; Figure 1). Between-group effect sizes for RAID total scores (Figure 2) met thresholds for small to moderate levels of importance by Cohen's d Rule for Change Interpretation in both sarilumab dose groups versus placebo at Weeks 12 and 24 (TARGET), and in the sarilumab $200 \mathrm{mg}$ group versus ADA at Week $24(\mathrm{MONARCH})^{30}$.

Domain scores. Changes from baseline in individual domain scores were significantly greater with sarilumab compared to placebo for differences between groups (all nominal $\mathrm{p}<0.05$ except sleep domain; Figure 3). In MONARCH, sarilumab treatment showed greater improvement compared with ADA only in the functional impairment domain at Week 12, and in all domains by Week 24. Moderate benefits were reported in the pain domain at Week 12 (effect sizes of 0.54 and 0.58 for sarilumab $150 \mathrm{mg}$ and $200 \mathrm{mg}$, respectively, vs placebo) and at Week 24 in TARGET (effect sizes of 0.54 and 0.68 for sarilumab $150 \mathrm{mg}$ and $200 \mathrm{mg}$ vs placebo; all nominal $\mathrm{p}<0.05$ ). In addition, most other domains (other than sleep) met thresholds for small importance at Week 24 in both studies $^{30}$.

Responder analyses, $M C I D \geq 3$. In TARGET, greater proportions of patients in the sarilumab $150 \mathrm{mg}$ and $200 \mathrm{mg}$ groups versus placebo were responders defined by an MCID $\geq 3$ (nominal $\mathrm{p} \leq 0.0001$ at Week 12 for both doses; nominal $\mathrm{p} \leq 0.01$ and nominal $\mathrm{p} \leq 0.0001$ for sarilumab $150 \mathrm{mg}$ and $200 \mathrm{mg}$, respectively, at Week 24; Figure 4A). In MONARCH, a greater proportion of the sarilumab $200 \mathrm{mg}$ group versus ADA were responders (nominal $\mathrm{p} \leq 0.01$ at both Weeks 12 and 24; Figure 4A).

Table 1. Patient demographics and disease characteristics.

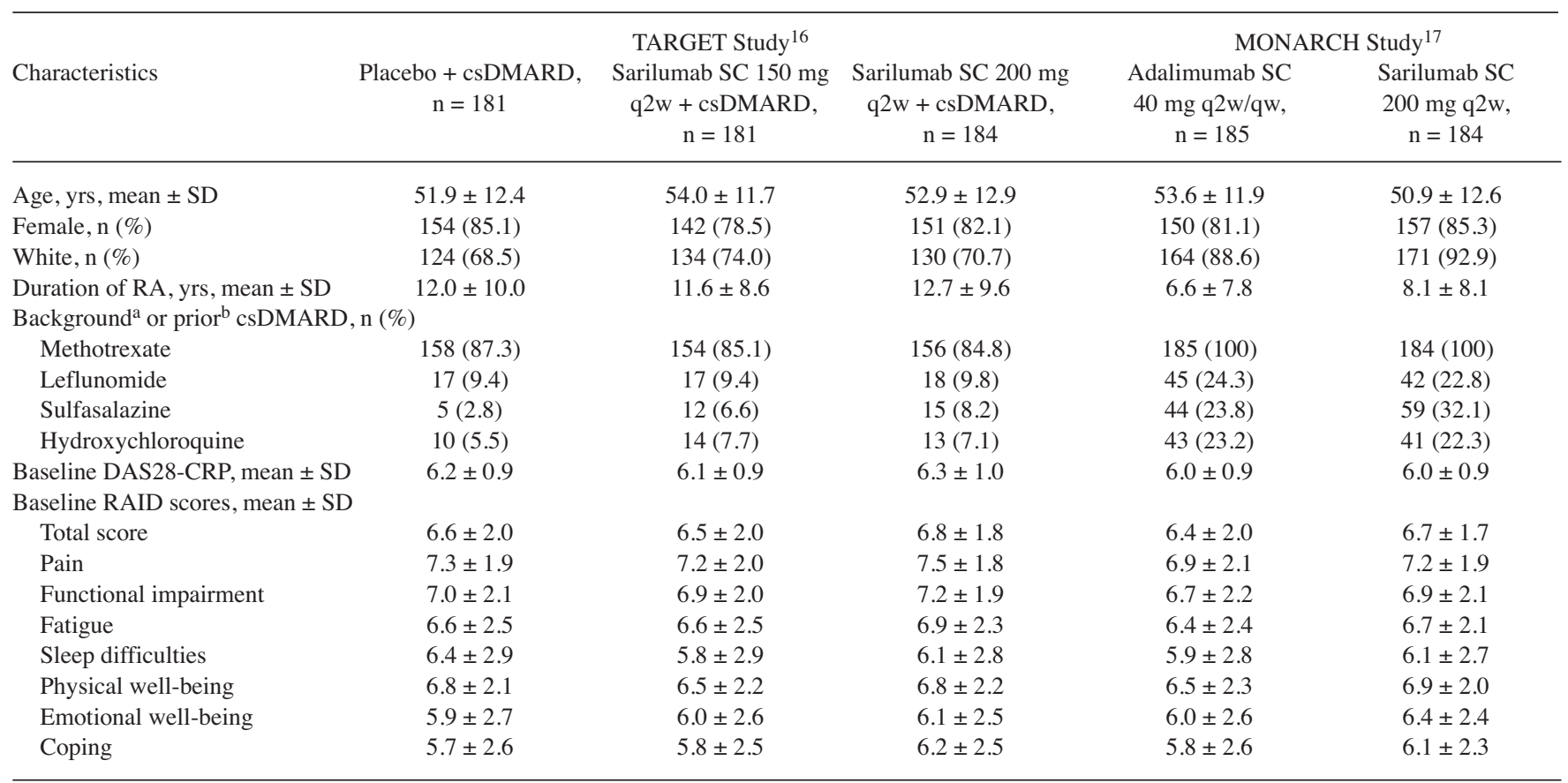

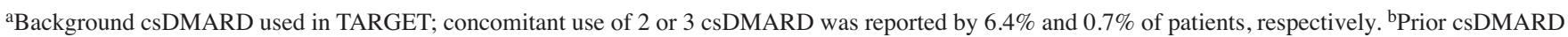
other than methotrexate used in MONARCH: named csDMARD were included if used in > 5\% of the population. DAS28-CRP: 28-joint Disease Activity Score using C-reactive protein; csDMARD: conventional synthetic disease-modifying antirheumatic drug; qw: once weekly; q2w: every 2 weeks; RA: rheumatoid arthritis; SC: subcutaneous; RAID: RA Impact of Disease scale.

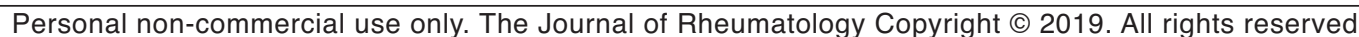




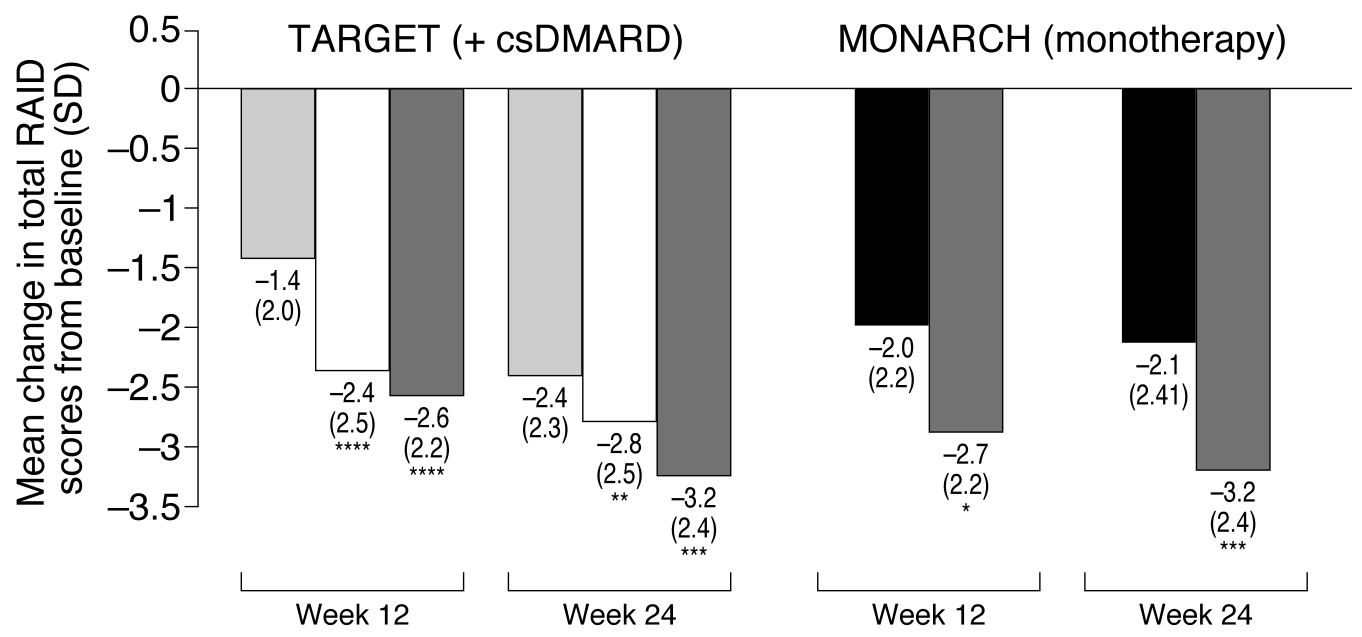

Placebo $\square$ Sarilumab SC 150 mg q2w $\square$ Sarilumab SC 200 mg q2w

Adalimumab SC $40 \mathrm{mg}$ q2w/qw

Figure 1. Mean change in total Rheumatoid Arthritis Impact of Disease (RAID) scores from baseline in TARGET (+ csDMARD) and MONARCH (monotherapy). * Nominal $\mathrm{p} \leq 0.05$; ** nominal $\mathrm{p} \leq 0.01$; *** nominal $\mathrm{p} \leq 0.001$; $* * * *$ nominal $\mathrm{p} \leq 0.0001$ all versus placebo (TARGET) or adalimumab (MONARCH). csDMARD: conventional synthetic disease-modifying antirheumatic drug; qw: once weekly; q2w: every 2 weeks; SC: subcutaneous.

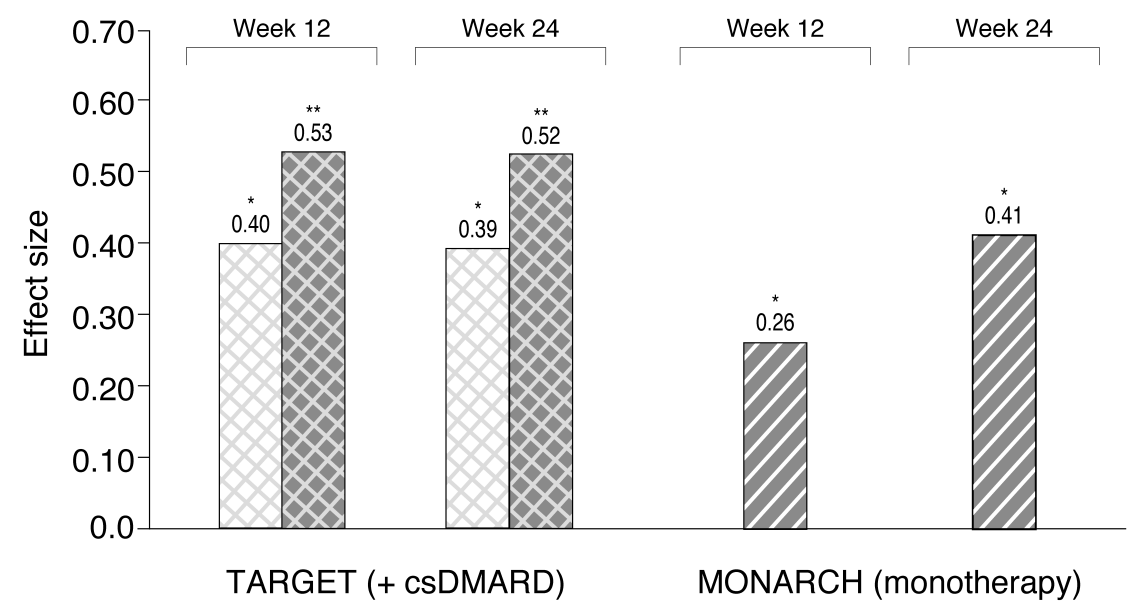

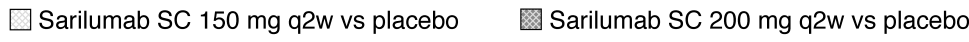

Sarilumab SC $200 \mathrm{mg}$ q2w vs adalimumab SC $40 \mathrm{mg}$ q2w/qw

Figure 2. Between-group effect sizes on Rheumatoid Arthritis Impact of Disease total score, sarilumab $150 \mathrm{mg}$ or $200 \mathrm{mg}$ versus placebo (TARGET: + csDMARD) or adalimumab (MONARCH: monotherapy). Cohen's d Rule for Change Interpretation: important: $\mathrm{d} \leq-0.8$; moderate: -0.8 $<\mathrm{d} \leq-0.5$; and small: $-0.5<\mathrm{d} \leq-0.2^{25}$. Nominal $\mathrm{p} \leq 0.05$; ** nominal $\mathrm{p} \leq 0.01$; versus placebo (TARGET) or adalimumab (MONARCH) for the difference between groups in the least-squares mean change from baseline. csDMARD: conventional synthetic disease-modifying antirheumatic drug; qw: once weekly; q2w: every 2 weeks; SC: subcutaneous.

$M C I D \geq 50 \%$. There were greater proportions of responders in both sarilumab dose groups in TARGET than in the placebo group (nominal $\mathrm{p} \leq 0.001$ at Week 12; nominal $\mathrm{p} \leq 0.01$ and nominal $\mathrm{p} \leq 0.001$ for sarilumab $150 \mathrm{mg}$ and
$200 \mathrm{mg}$, respectively, at Week 24). In MONARCH, greater improvement with sarilumab $200 \mathrm{mg}$ versus ADA was reported at Week 24 (nominal $\mathrm{p} \leq 0.05$; Figure 4B).

PASS. Absolute total RAID scores $\leq 3$ were reported by both 


\section{A) Week 12}

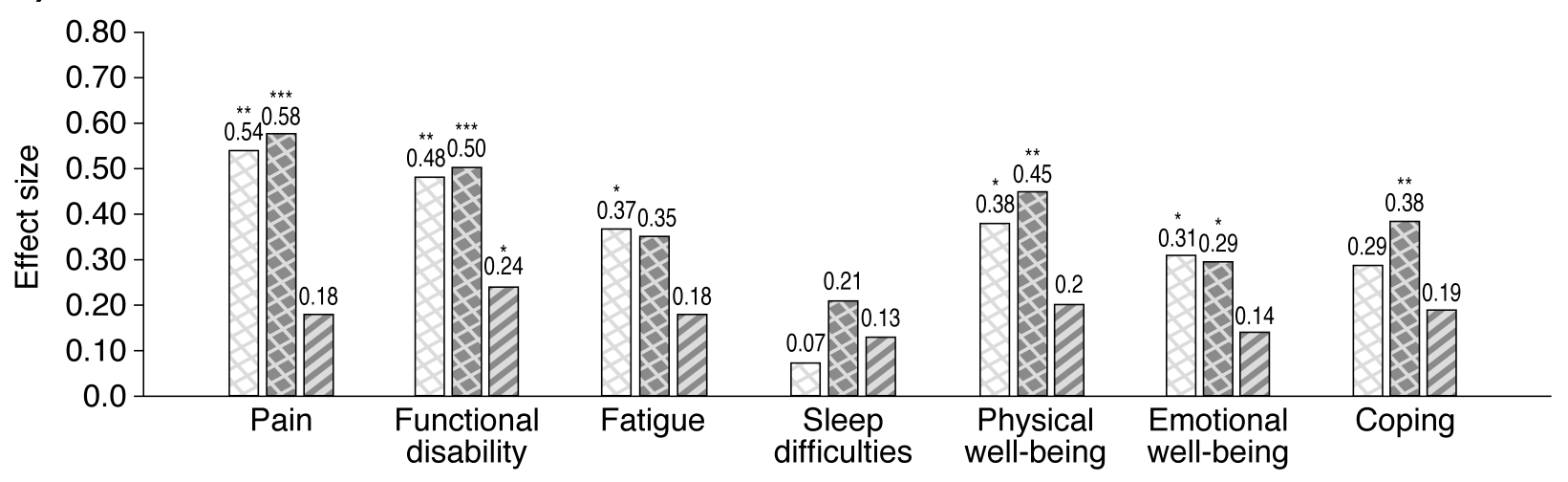

\section{B) Week 24}

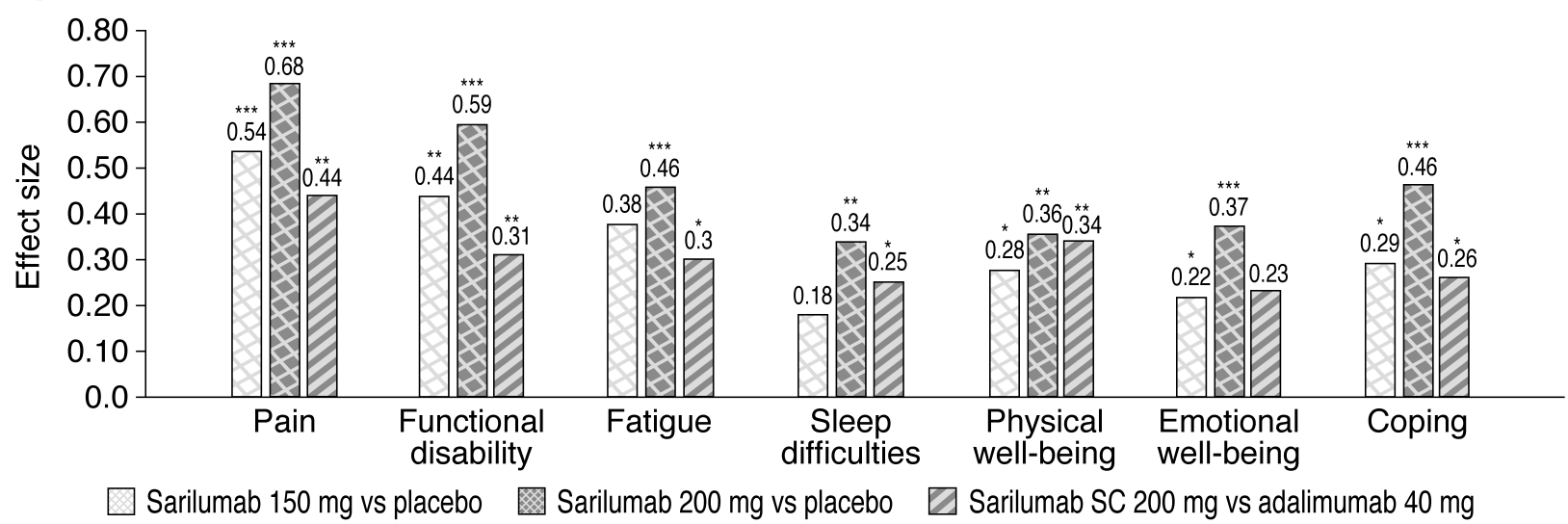

Figure 3. Between-group effect sizes on Rheumatoid Arthritis Impact of Disease domain scores in TARGET, sarilumab 150 mg + csDMARD or 200 $\mathrm{mg}+\mathrm{csDMARD}$ versus placebo; and in MONARCH, monotherapy with sarilumab $200 \mathrm{mg}$ versus adalimumab $40 \mathrm{mg}$ : (A) Week 12 , (B) Week 24. Cohen's $d$ Rule for Change Interpretation: important: $\mathrm{d} \leq-0.8$; moderate: $-0.8<\mathrm{d} \leq-0.5$; and small: $-0.5<\mathrm{d} \leq-0.2^{25}$. Nominal $\mathrm{p} \leq 0.05$; ** nominal $\mathrm{p} \leq 0.01$; *** nominal $\mathrm{p} \leq 0.001$; all versus placebo for the difference between groups in the least-squares mean change from baseline. csDMARD: conventional synthetic disease-modifying antirheumatic drug; SC: subcutaneous.

sarilumab dose groups versus the placebo group in TARGET at Week 12 (sarilumab $150 \mathrm{mg}$, nominal $\mathrm{p} \leq 0.01$; sarilumab $200 \mathrm{mg}$, nominal $\mathrm{p} \leq 0.001$ ) and Week 24 (sarilumab $200 \mathrm{mg}$, nominal $\mathrm{p} \leq 0.05$; sarilumab $200 \mathrm{mg}$, nominal $\mathrm{p} \leq 0.001$ ). In MONARCH at Week 24, a greater proportion of patients receiving sarilumab $200 \mathrm{mg}$ than ADA were defined as responders (nominal $\mathrm{p} \leq 0.01$; Figure $4 \mathrm{C}$ ).

\section{DISCUSSION}

The benefits of sarilumab treatment as combination therapy with csDMARD or as monotherapy across a range of PRO have been reported in MTX-IR and TNF-IR populations, including patient global assessment of disease activity, pain, physical function, fatigue, and general health status. Based on the patient-reported RAID scale, data collected in the TARGET and MONARCH RCT indicate that sarilumab 150 mg or $200 \mathrm{mg} \mathrm{q} 2 \mathrm{w}$ given as combination therapy with a csDMARD or as $200 \mathrm{mg}$ monotherapy reduced the effects of RA on patients' lives to a greater extent than placebo plus csDMARD or ADA SC $40 \mathrm{mg}$ q2w or once weekly mono- therapy. Mean baseline scores ranged from 6.4 to 6.8, indicating a high impact of disease in these trial populations. In both the TARGET and MONARCH RCT, the benefits of sarilumab treatment on symptoms and impact of disease were clinically meaningful when assessed by 2 definitions of MCID and by PASS, with differential effects compared with placebo or ADA across the majority of RAID domains (with the exception of sleep for sarilumab vs placebo in the TARGET study), with marked improvements in RAID total scores and domains of pain and functional impairment across all sarilumab treatment groups.

The relatively new RAID scale has to date been applied in only 1 other clinical trial ${ }^{15}$, a smaller, open-label, single-arm study of etanercept (ETN) $50 \mathrm{mg} / \mathrm{wk}$. In that study, $56 \%$ of 120 patients with active RA reported total RAID scores $\leq 3.0$ at Week 12, indicating reduced disease impact from baseline ${ }^{15}$. In comparison, patients in TARGET and MONARCH had longer disease duration and higher baseline RAID scores than in the ETN study ${ }^{15,16,17}$.

In these 2 larger RCT, $35 \%$ of sarilumab-treated patients Personal non-commercial use only. The Journal of Rheumatology Copyright @ 2019 . All rights reserved. 
A) $M C I D \geq 3$

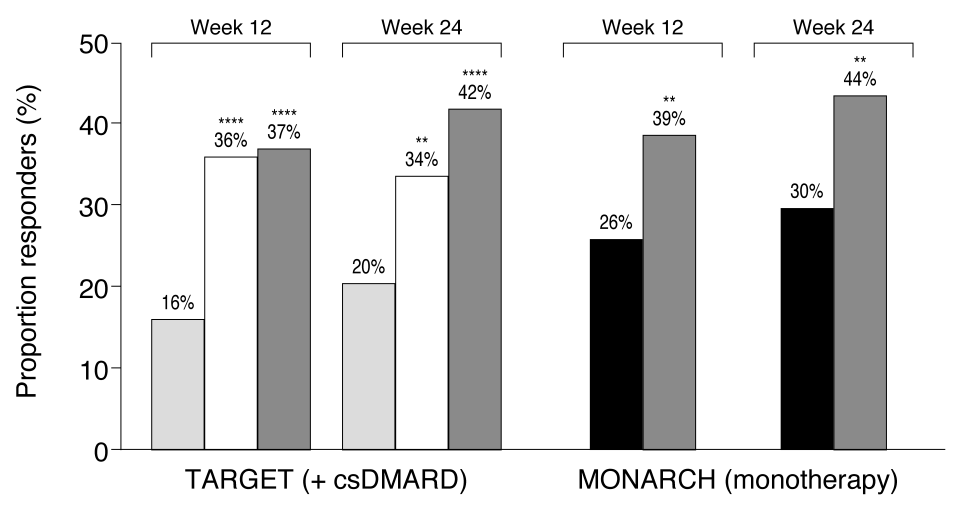

B) $M C I D \geq 50 \%$ of baseline RAID score

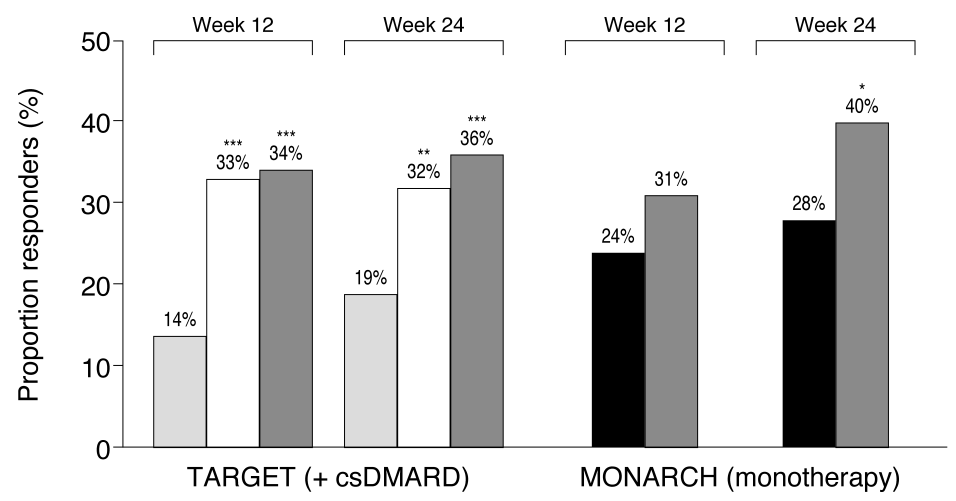

C) RAID score $\leq 3$

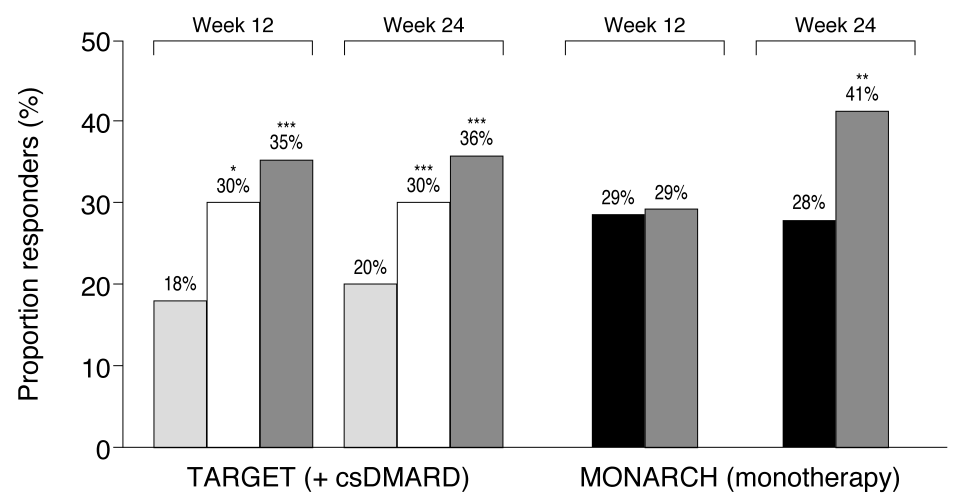

$\square$ Placebo $\square$ Sarilumab SC $150 \mathrm{mg}$ q2w $\square$ Sarilumab SC $200 \mathrm{mg}$ q2w

- Adalimumab SC $40 \mathrm{mg}$ q2w/qw

Figure 4. Proportion of patients in TARGET (+ csDMARD) and MONARCH (monotherapy) who (A and B) reported improvements in RAID scores $\geq$ MCID; or (C) reached a patient-acceptable symptom-state of 3 or lower. * Nominal $\mathrm{p} \leq 0.05$; $* *$ nominal $\mathrm{p} \leq 0.01$; *** nominal $\mathrm{p} \leq 0.001$; **** nominal $\mathrm{p} \leq 0.0001$, all versus placebo (TARGET) or adalimumab (MONARCH). csDMARD: conventional synthetic disease-modifying antirheumatic drug; MCID: minimal clinically important differences; qw: once weekly; q2w: every 2 weeks; RAID: Rheumatoid Arthritis Impact of Disease; SC: subcutaneous.

in TARGET at Week 12 and 36\% at Week 24 reported RAID scores $\leq 3$; and in MONARCH it was $41 \%$ at Week 24 .

Newer PRO measures such as the RAID scale are revealing the additional importance of evaluating multidimensional patient outcomes with content and construct validity, responsiveness, and precision. It is now widely 
recognized that PRO should reveal what is important for patients, and that they should be developed with patient input $^{32,33}$. RAID was developed by a EULAR international task force of clinicians and patients to provide a single instrument that integrates all relevant patient domains, with relevance in different disease states, countries, and cultures, and it was designed to better quantify the experience of living with RA. Several studies have shown that the domains assessed in RAID are applicable and important for patients $8,10,12,25,34$. The advantage of sarilumab treatment over ADA and placebo for improving RAID domains in these trials offers important information for physicians to consider in the context of shared treatment decision making ${ }^{35}$.

Pain, fatigue, sleep disturbance, and ability to cope are all symptoms that are of importance to patients with RA, but not all (e.g., sleep and ability to cope) are routinely assessed in RA RCT, or even in clinical practice ${ }^{36}$. RAID is unique in that it not only assesses patient-reported symptoms such as pain, but also fatigue, sleep disturbance, and coping. Fatigue, frequently reported in RA, can severely affect all aspects of health-related quality of life (HRQOL), with a multifactorial origin, not just inflammation but personal factors and psychological distress as well ${ }^{37}$.

In this analysis, we noted some differences in responses to treatment: sleep and coping were less responsive than other domains, suggesting these may be less amenable to short-term treatment effects of DMARD and biologics than, for example, pain. It appears that sleep and coping, in particular, are less accessible to biologic treatment than other patient-reported domains of impact. This raises the question of whether these aspects of HRQOL are less directly linked to the inflammatory process than, for example, pain ${ }^{14}$. This is consistent with findings from other RCT of DMARD with other mechanisms of action, in which sleep responsiveness in particular has been reported as less than other PRO ${ }^{14,38}$.

Our findings must be considered in light of some study limitations. While the RAID data were included in the statistical hierarchy in MONARCH and TARGET, results were considered after the break in the hierarchy; therefore, $\mathrm{p}$ values were not controlled for multiplicity, and are nominal. Hence, we applied multiple approaches to assess the clinical relevance of the observed results, including Cohen's d, responder analysis using 2 different MCID definitions, and PASS. All the approaches consistently indicated clinically meaningful improvements across the RAID domains. Further investigation of the relationships of the endpoints with RAID, and any added value of RAID within the context of a clinical trial, is warranted for a separate study. Nonetheless, despite the relative novelty of the RAID scale, a range of tests support our interpretation of the present results. In addition, because ADA is usually used as combination therapy, the added value of our findings should not be seen as a comparison with ADA only, but also as further validating a recent outcome measure, the RAID.
While the extreme burden on patients with RA caused by their joint damage is widely recognized ${ }^{39,40,41}$, other manifestations of this systemic disease including multiple comorbidities and psychosocial outcomes continue to be revealed ${ }^{42,43}$. Hence, in addition to the clinical markers of disease activity that are unequivocally necessary for informing treatment decisions in RA, assessing improvement on PRO including HRQOL reveals the ultimate benefit of treatment in reducing patient burden ${ }^{39,40,44}$. The objective of the RAID scale is to provide a comprehensive assessment of the effects of treatment on patient burden, and from their perspective.

As a relatively new measure, RAID has yet to be widely applied in either RA RCT or clinical practice settings. Although its use is increasing, its inclusion in large prospective studies will provide more evidence of its sensitivity ${ }^{8}$ and assessment of acceptable levels of missing data and MCID/PASS definitions, while data from clinical practice settings in diverse patient populations will indicate its generalizability.

Our analyses indicate that the RAID scale efficiently evaluated the benefits of sarilumab treatment on patientreported effects of RA in both the TARGET and the MONARCH RCT.

\section{ACKNOWLEDGMENT}

The authors thank the patients, their families, and all investigators involved in the sarilumab studies.

\section{REFERENCES}

1. Strand V, Khanna D. The impact of rheumatoid arthritis and treatment on patients' lives. Clin Exp Rheumatol 2010;28:S32-40.

2. Rendas-Baum R, Bayliss M, Kosinski M, Raju A, Zwillich SH, Wallenstein GV, et al. Measuring the effect of therapy in rheumatoid arthritis clinical trials from the patient's perspective. Curr Med Res Opin 2014;30:1391-403.

3. Matcham F, Scott IC, Rayner L, Hotopf M, Kingsley GH, Norton S, et al. The impact of rheumatoid arthritis on quality-of-life assessed using the SF-36: a systematic review and meta-analysis. Semin Arthritis Rheum 2014;44:123-30.

4. European Medicines Agency. Guideline on clinical investigation of medicinal products other than NSAIDs for treatment of rheumatoid arthritis. [Internet. Accessed May 8, 2019.] Available from: www.ema.europa.eu/docs/en_GB/document_library/Scientific_ guideline/2015/06/WC500187583.pdf

5. Kirwan JR, Tugwell PS. Overview of the patient perspective at OMERACT 10 - Conceptualizing methods for developing patient-reported outcomes. J Rheumatol 2011;38:1699-701.

6. Kirwan JR, Hewlett SE, Heiberg T, Hughes RA, Carr M, Hehir M, et al. Incorporating the patient perspective into outcome assessment in rheumatoid arthritis - Progress at OMERACT 7. J Rheumatol 2005;32:2250-6.

7. Felson DT, Anderson JJ, Boers M, Bombardier C, Chernoff M, Fried B, et al. The American College of Rheumatology preliminary core set of disease activity measures for rheumatoid arthritis clinical trials. The Committee on Outcome Measures in Rheumatoid Arthritis Clinical Trials. Arthritis Rheum 1993;36:729-40.

8. Gossec L, Paternotte S, Aanerud GJ, Balanescu A, Boumpas DT, Carmona L, et al. Finalisation and validation of the Rheumatoid Arthritis Impact of Disease score, a patient-derived composite measure of impact of rheumatoid arthritis: A EULAR initiative. Ann Rheum Dis 2011;70:935-42.

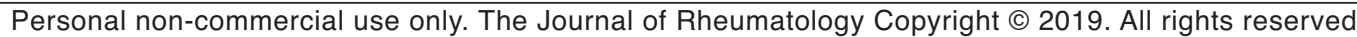


9. Gullick NJ, Scott DL. Rheumatoid arthritis: clinical utility of the RAID (RA Impact of Disease) score. Nat Rev Rheumatol 2011;7:499-500.

10. Heiberg T, Austad C, Kvien TK, Uhlig T. Performance of the Rheumatoid Arthritis Impact of Disease (RAID) score in relation to other patient-reported outcomes in a register of patients with rheumatoid arthritis. Ann Rheum Dis 2011;70:1080-2.

11. Dougados M, Brault Y, Logeart I, van der Heijde D, Gossec L, Kvien T. Defining cut-off values for disease activity states and improvement scores for patient-reported outcomes: The example of the Rheumatoid Arthritis Impact of Disease (RAID). Arthritis Res Ther 2012;14:R129.

12. Hewlett S, Kirwan J, Bode C, Cramp F, Carmona L, Dures E, et al. The revised Bristol Rheumatoid Arthritis Fatigue measures and the Rheumatoid Arthritis Impact of Disease scale: Validation in six countries. Rheumatology 2018;57:300-8.

13. Ferreira RJO, Dougados M, Kirwan JR, Duarte C, de Wit M, Soubrier M, et al; CoimbRA investigators, RAID investigators and COMEDRA investigators. Drivers of patient global assessment in patients with rheumatoid arthritis who are close to remission: an analysis of 1588 patients. Rheumatology 2017;56:1573-8.

14. Avila-Ribeiro P, Brault Y, Dougados M, Gossec L. Psychometric properties of sleep and coping numeric rating scales in rheumatoid arthritis: a subanalysis of an etanercept trial. Clin Exp Rheumatol 2017;35:786-90

15. Dougados M, Ripert M, Hilliquin P, Brocq O, Brault Y, Logeart I. Onset of action of etanercept in rheumatoid arthritis based on patient-reported outcomes. Clin Exp Rheumatol 2012;30:266-8.

16. Fleischmann R, van Adelsberg J, Lin Y, Castelar-Pinheiro GD, Brzezicki J, Hrycaj P, et al. Sarilumab and nonbiologic disease-modifying antirheumatic drugs in patients with active rheumatoid arthritis and inadequate response or intolerance to tumor necrosis factor inhibitors. Arthritis Rheum 2017;69:277-90.

17. Burmester GR, Lin Y, Patel R, van Adelsberg J, Mangan EK, Graham NM, et al. Efficacy and safety of sarilumab monotherapy versus adalimumab monotherapy for the treatment of patients with active rheumatoid arthritis (MONARCH): a randomised, double-blind, parallel-group phase III trial. Ann Rheum Dis 2017;76:840-7

18. Fries JF, Spitz P, Kraines RG, Holman HR. Measurement of patient outcome in arthritis. Arthritis Rheum 1980;23:137-45.

19. European League Against Rheumatism. EULAR tools and products - The EULAR RAID and PsAID Questionnaires. [Internet. Accessed May 8, 2019.] Available from: www.eular.org/tools_products_.cfm

20. Hifinger M, Putrik P, Ramiro S, Keszei AP, Hmamouchi I, Dougados M, et al. In rheumatoid arthritis, country of residence has an important influence on fatigue: results from the multinational COMORA study. Rheumatology 2016;55:735-44.

21. Gossec L, Cantagrel A, Soubrier M, Berthelot JM, Joubert JM, Combe B, et al. An e-health interactive self-assessment website $\left(\right.$ Sanoia $\left.{ }^{\circledR}\right)$ in rheumatoid arthritis. A 12-month randomized controlled trial in 320 patients. Joint Bone Spine 2018;85:709-14.

22. Aletaha D, Neogi T, Silman AJ, Funovits J, Felson DT, Bingham CO 3rd, et al. 2010 rheumatoid arthritis classification criteria: An American College of Rheumatology/European League Against Rheumatism collaborative initiative. Arthritis Rheum 2010; 62:2569-81.

23. Hochberg MC, Chang RW, Dwosh I, Lindsey S, Pincus T, Wolfe F. The American College of Rheumatology 1991 revised criteria for the classification of global functional status in rheumatoid arthritis. Arthritis Rheum 1992;35:498-502.

24. Salaffi F, Di Carlo M, Vojinovic J, Tincani A, Sulli A, Soldano S, et al. Validity of the Rheumatoid Arthritis Impact of Disease (RAID) score and definition of cut-off points for disease activity states in a population-based European cohort of patients with rheumatoid arthritis. Joint Bone Spine 2018;85:317-22.

25. ter Wee MM, van Tuyl LH, Blomjous BS, Lems WF, Boers M, Terwee CB. Content validity of the Dutch Rheumatoid Arthritis Impact of Disease (RAID) score: results of focus group discussions in established rheumatoid arthritis patients and comparison with the International Classification of Functioning, Disability and Health core set for rheumatoid arthritis. Arthritis Res Ther 2016;18:22.

26. Wells G, Anderson J, Beaton D, Bellamy N, Boers M, Bombardier C, et al. Minimal clinically important difference module: summary, recommendations, and research agenda. J Rheumatol 2001;28:452-4

27. Tubach F, Ravaud P, Baron G, Falissard B, Logeart I, Bellamy N, et al. Evaluation of clinically relevant changes in patient reported outcomes in knee and hip osteoarthritis: the minimal clinically important improvement. Ann Rheum Dis 2005;64:29-33.

28. Tubach F, Ravaud P, Baron G, Falissard B, Logeart I, Bellamy N, et al. Evaluation of clinically relevant states in patient reported outcomes in knee and hip osteoarthritis: the patient acceptable symptom state. Ann Rheum Dis 2005;64:34-7.

29. Tubach F, Dougados M, Falissard B, Baron G, Logeart I, Ravaud P. Feeling good rather than feeling better matters more to patients. Arthritis Rheum 2006;55:526-30.

30. Cohen J. Statistical power analysis for the behavioral sciences. 2nd ed. Hillsdale, NJ: Lawrence Erlbaum Associates; 1988.

31. Strand V, Reaney M, Chen CI, Proudfoot CW, Guillonneau S, Bauer $\mathrm{D}$, et al. Sarilumab improves patient-reported outcomes in rheumatoid arthritis patients with inadequate response/intolerance to tumour necrosis factor inhibitors. RMD Open 2017;3:e000416.

32. Tugwell P, Boers M, Brooks P, Simon L, Strand V, Idzerda L. OMERACT: an international initiative to improve outcome measurement in rheumatology. Trials 2007;8:38.

33. U.S. Food and Drug Administration. Patient-reported outcome measures: use in medical product development to support labeling claims. December 2009. [Internet. Accessed May 9, 2019.] Available from: https://www.fda.gov/downloads/drugs/guidances/ucm193282.pdf

34. Cheung PP, Lahiri M, March L, Gossec L. Patient-reported outcomes in Asia: evaluation of the properties of the Rheumatoid Arthritis Impact of Disease (RAID) score in multiethnic Asian patients with rheumatoid arthritis. Clin Rheumatol 2017; 36:1149-54.

35. Fraenkel L, Nowell WB, Michel G, Wiedmeyer C. Preference phenotypes to facilitate shared decision-making in rheumatoid arthritis. Ann Rheum Dis 2017;77:678-83.

36. Gossec L, Dougados M, Dixon W. Patient-reported outcomes as end points in clinical trials in rheumatoid arthritis. RMD Open 2015;1:e000019.

37. Hewlett S, Chalder T, Choy E, Cramp F, Davis B, Dures E, et al. Fatigue in rheumatoid arthritis: time for a conceptual model. Rheumatology 2011;50:1004-6.

38. Gossec L, Danre A, Combe B, Le Loet X, Tebib J, Sibilia J, et al. Improvement in patient-reported outcomes after rituximab in rheumatoid arthritis patients: An open-label assessment of 175 patients. Joint Bone Spine 2015;82:451-4.

39. Uhlig T, Moe RH, Kvien TK. The burden of disease in rheumatoid arthritis. Pharmacoeconomics 2014;32:841-51.

40. Peterson C, DeGue S, Florence C, Lokey CN. Lifetime economic burden of rape among U.S. adults. Am J Prev Med 2017; 52:691-701.

41. Shin SY, Katz P, Wallhagen M, Julian L. Cognitive impairment in persons with rheumatoid arthritis. Arthritis Care Res 2012; 64:1144-50.

42. Cutolo M, Kitas GD, van Riel PL. Burden of disease in treated rheumatoid arthritis patients: going beyond the joint. Semin Arthritis Rheum 2014;43:479-88. 
43. Matcham F, Ali S, Irving K, Hotopf M, Chalder T. Are depression and anxiety associated with disease activity in rheumatoid arthritis? A prospective study. BMC Musculoskelet Disord 2016;17:155.

44. Smolen JS, Landewe R, Breedveld FC, Dougados M, Emery P,
Gaujoux-Viala C, et al. EULAR recommendations for the management of rheumatoid arthritis with synthetic and biological disease-modifying antirheumatic drugs. Ann Rheum Dis 2010;69:964-75. 